\title{
Comparison of hybrid procedure and open surgical revascularization for multilevel infrainguinal arterial occlusive disease
}

This article was published in the following Dove Press journal:

Clinical Interventions in Aging

22 September 2014

Number of times this article has been viewed

\section{Min Zhou \\ Dian Huang \\ Chen Liu \\ Zhao Liu \\ Min Zhang \\ Tong Qiao \\ Chang-Jian Liu}

Department of Vascular Surgery, Affiliated Drum Tower Hospital of Nanjing University Medical School, Nanjing, People's Republic of China
Correspondence: Tong Qiao Department of Vascular Surgery, Affiliated Drum Tower Hospital of Nanjing University Medical School Zhongshan Road 321, Nanjing 210008, People's Republic of China Email qiaotongmail@aliyu.com

Chang-Jian Liu

Department of Vascular Surgery, Affiliated Drum Tower Hospital of Nanjing University Medical School Zhongshan Road 321, Nanjing 210008,

People's Republic of China

Email zhouminnju@gmail.com
Objective: To compare outcomes of hybrid (combined surgical and endovascular) procedures (HYBRID) with open surgical reconstructions (OPEN) in patients with multilevel infrainguinal artery occlusive diseases.

Design: Case series study with retrospective analysis of prospectively collected nonrandomized data.

Methods: Between 2008 and 2012, 64 patients underwent OPEN and 43 underwent HYBRID. Patient characteristics, technique success, clinical improvement, and procedure-related morbidity were reviewed and compared. Patency rates and limb salvages were analyzed and compared using Kaplan-Meier life tables. Cox regression analyses were used to assess the influence of various risk factors on primary patency.

Results: HYBRID patients were older and presented with worse New York Heart Association function compared with OPEN patients. The increase in the ankle-brachial index and improvement of Ruthford category after procedures were equivalent between two groups, but HYBRID patients had shorter hospital length of stay $(7.6 \pm 12.0$ versus $15.5 \pm 17.3 ; P=0.018)$ and less overall perioperative morbidity ( $12 \%$ versus $28 \% ; P=0.042)$ compared with OPEN patients. No statistically significant difference in 36-month primary ( $47.1 \% \pm 7.1 \%$ versus $50.1 \% \pm 9.4 \% ; P=0.418)$, assisted primary $(57.0 \% \pm 7.9 \%$ versus $62.4 \% \pm 9.2 \% ; P=0.517)$, or secondary $(82.0 \% \pm 6.8 \%$ versus $83.1 \% \pm 7.3 \% ; P=0.445$ ) patency was seen between the two groups. Limb salvage rates of HYBRID vs OPEN at 3 years were similar $(76.3 \% \pm 9.3 \%$ versus $80.4 \% \pm 8.2 \% ; P=0.579)$. Critical limb ischemia was a negative predictor of long-term patency of patients in both the HYBRID and OPEN groups ( $P=0.012$ and $P<0.001$, respectively), and the presence of diabetes and renal insufficiency were another two independent predictors of decreased primary patency for HYBRID ( $P=0.017$ and $P=0.019$, respectively).

Conclusion: Multilevel infrainguinal artery occlusive diseases could be treated by hybrid procedure, with shorter hospitalization, less perioperative morbidity, and similar early- and longterm efficacy compared with open revascularization. A hybrid procedure should be considered for patients with high surgical risk, but critical limb ischemia, diabetes, and renal insufficiency could compromise its long-term patency.

Keywords: hybrid procedure, atherosclerotic occlusive disease, endovascular treatment

\section{Introduction}

Chronic occlusive atherosclerosis of the infrainguinal vessel is the most prevalent manifestation of peripheral arterial disease among the elderly. The mainstay of treatment for infrainguinal peripheral arterial disease has been arterial bypass surgery, but recent advanced endovascular interventions have challenged surgery as the first-line treatment. ${ }^{1}$ The Trans-Atlantic Inter-Society Consensus (TASC) classification suggests 
the choices for first-line therapy and predicts successful intervention after endovascular or open surgical therapy mainly according to lesion location and length. ${ }^{2}$ However, infrainguinal peripheral arterial disease does not uncommonly affect multiple levels of the femoral, popliteal, tibial, and peroneal arteries, especially in patients with critical limb ischemia (CLI). The anatomic variables, combined with patient-specific comorbidities, make therapeutic decisions more complex. ${ }^{3}$ Fortunately, as vascular surgeons have embraced the independent performance of endovascular procedures in the operating room during the last few decades, endovascular interventions can be coupled with open revascularization, creating the so-called hybrid procedures. ${ }^{4}$ The common occurrence of multilevel infrainguinal occlusive disease (MIOD) has increased the need for a hybrid procedure. ${ }^{5}$ At this time, hybrid procedures are reported to consist of 5\%-21\% of the total number of vascular reconstructions, ${ }^{6,7}$ and many authors have demonstrated the efficacy of hybrid procedure for the treatment of severe multilevel lower extremity arterial disease..$^{8-10}$

The purpose of this study was to review our contemporary experience treating chronic MIOD with hybrid procedure (HYBRID) and to compare the results with those of open revascularization (OPEN). Particular attention was given to perioperative safety, technical outcomes, and longterm procedural durability for both OPEN and HYBRID treatments.

\section{Patients and methods Study design}

A nonrandomized retrospective study was undertaken, including consecutive patients with obstructive arterial disease at two or more levels among the femoral, popliteal, tibial, and peroneal arteries. The patients were treated with either OPEN or HYBRID procedures. These procedures were performed in a single session in all patients. The study excluded patients with concomitant aortoiliac disease, popliteal aneurysm, popliteal entrapment syndrome, and acute limb embolization. This type of study did not require the approval of the institutional review board, and all patients provided informed consent before treatment.

\section{Patients and data collection}

All consecutive MIOD patients undergoing either HYBRID or OPEN procedures between January 2008 and December 2012 were included in this study. For the patients who suffered from bilateral disease, only the first affected limbs during the study period were included. Preoperative, intraoperative, and follow-up information was available for all patients, and it was prospectively collected and retrospectively reviewed. Demographic features, comorbidities, and indications for intervention were recorded. All patients underwent preoperative peripheral arterial evaluation with physical examination, measurement of ankle-brachial pressure index (ABI), and either digital subtraction angiography or computed tomography angiography. The TASC classifications of lesions and the number of patent tibial arteries were also recorded.

\section{Revascularization technique: open surgery}

The details of open surgery included conduit types and sites of anastomosis. The autovein graft was used for infrainguinal bypass, with the reversed saphenous vein being used most frequently. When this was absent, a polytetrafluoroethylene graft was used for bypass to the above-knee popliteal artery, and either an arm vein or a composite polytetrafluoroethylenevein graft was considered for below-knee arteries. The extent of the bypass graft, proximal to distal, was determined by the pattern of occlusive disease. Extensive occlusive disease involving both the femoral-popliteal segment and the infrageniculate arteries was treated with a bypass graft originating from the femoral artery and extending the length of the limb to a target site in the tibial or pedal arteries. Those with severe infrageniculate occlusive disease, but with patent and well-preserved femoral-popliteal vessels, underwent bypass graft from the popliteal artery to the tibial or pedal arteries. Patients who required popliteal-distal bypass but also had a focal femoral bifurcation lesion were treated by common femoral artery (CFA) endarterectomy and patch angioplasty simultaneously.

\section{Revascularization technique: hybrid procedure}

These procedures were performed in the hybrid operating room, equipped with a Philips Allura Xper angiographic $\mathrm{X}$-ray system and a moveable radiolucent surgical table. The following three techniques were applied most frequently in this study.

\section{CFA endarterectomy/patch angioplasty with SFA or distal endovascular intervention}

Patients with evidence for significant CFA occlusive disease with TASC II A/B femoropopliteal lesion were considered for this technique. CFA and femoral bifurcation was exposed beyond the inguinal ligament. Puncture of the CFA was 
performed to establish guidewire access across the distal lesion. Longitudinal arteriotomy was created, and standard endarterectomy was performed after systemic anticoagulation with heparin $(100 \mathrm{U} / \mathrm{kg})$. Patch angioplasty then was performed with Dacron or, rarely, a venous patch. Placement of sheath over the wire can be achieved in two ways: through the patch material or via the anastomosis. If guidewire access could not be obtained initially with puncture, it was then attempted after arteriotomy but before endarterectomy, and finally, if necessary, after endarterectomy with direct vision. Distal lesions were preferentially treated with angioplasty and selective stenting. Stents were reserved for residual stenosis greater than $30 \%$ and flow-limiting dissections. The type of self-expanding stent selected was determined by available inventory and operator preference.

\section{SFA endovascular intervention with popliteal-distal bypass}

Patients with evidence for TASC II A/B femoropopliteal lesions combined with TASC C/D popliteal-tibial disease were considered for this procedure. The autovein was identified and evaluated preoperatively by color duplex ultrasonography (CDU). First, the proximal and distal target arteries were accessed, vein was harvested, and tunneling of the venous graft was done, followed by systemic heparinization. We prefer to perform the distal anastomosis before the proximal. Before finishing the proximal anastomosis, a hydrophilic guidewire was advanced in a retrograde way into the superficial femoral artery (SFA) under fluoroscopic guidance just before placement of the last bite in the suture line. A long 7F sheath was advanced over the guidewire to accommodate the balloons and stents, which provided a more comfortable working length and allowed our hands to remain out of the field of radiation. After open transluminal angioplasty or stenting, the sheath was removed and the proximal suture line was finished.

\section{Femoropopliteal bypass with infrapopliteal (distal) endovascular intervention}

Patients with evidence for TASC II C/D femoropopliteal occlusion combined with TASC A/B popliteal-tibial disease were considered for this procedure. Typically, the proximal and distal target arteries were accessed, and a subsartorial tunnel was created. Then the patient was systemically heparinized with subsequent construction of the distal anastomosis in an end-to-side fashion. The vein or polytetrafluoroethylene graft went through the created tunnel, and then the proximal head of the graft was ligated and punctured, using a standard
Seldinger technique, and a short 7F sheath is was advanced over the guidewire. Then a 0.018 or 0.014 wire was accessed across the infrapopliteal lesion with fluoroscopic guidance. After the completion of transgraft angioplasty of the runoff vessels, the sheath was removed and the graft alignment checked again to ensure the absence of any twist. After that, proximal anastomosis was finished and blood flow was restored.

\section{Postoperative follow-up}

All patients were treated with low molecular weight heparin (4,100 IU twice daily) for 3 days and with dual antiplatelet therapy $(100 \mathrm{mg} /$ day aspirin and $75 \mathrm{mg} /$ day clopidogrel) for 3 months after operation, and thereafter with aspirin $(100 \mathrm{mg} /$ day) for life. The patients were followed-up by our vascular laboratory at 1, 3, and 6 months and at 6-month intervals thereafter for ABI measurements, graft or stent velocities, and patency by CDU. Patients with worsening clinical symptoms, physical examinations, and/or noninvasive studies were further assessed with computed tomography angiography. Digital subtraction angiography was carried out only in patients with positive clinical and instrumental examination to assess the need for further treatment and decide the type of therapy.

\section{Definitions and endpoints}

Technical success was defined as CDU or digital subtraction angiography-determined residual stenosis less than 30\%, and at least one patent tibial artery with uninterrupted flow to the pedal arch was achieved after revascularization. Perioperative morbidity and mortality included major complications and deaths, respectively, occurring during the first 30 days. Minor complications not requiring treatment were not included. Patency at follow-up was defined as less than $50 \%$ diameter stenosis determined by CDU. Primary, primary assisted, and secondary patency were determined in concordance with the Society for Vascular Surgery/American Association for Vascular Surgery guidelines. ${ }^{11}$

\section{Statistical analysis}

Data analysis was performed using IBM SPSS statistics version 19. Continuous variables were given as mean \pm standard deviation. Demographic comparisons were made using chi-square test for categorical variables and Mann-Whitney $U$-test for continuous variables. Kaplan-Meier survival curves for primary patency, primary assisted patency, secondary patency, and limb salvage were estimated, and the $\log$-rank $P$-value was used to compare the two procedures. 
The multivariate Cox proportional hazard model was used to identify independent predictors of patency. A value of $P<0.05$ was considered statistical significance.

\section{Results}

\section{Patient characteristics}

A total of 107 consecutive patients were treated (43 in HYBRID, 64 in OPEN). The median age was $65 \pm 13.2$ years (range, 52-90 years). Demographics, comorbidities, indications, and anatomic characteristics were reported in Tables 1 and 2 . In general, OPEN patients were typically younger $(61 \pm 14.5$ vs $70 \pm 10.2$ years; $P<0.001)$ and male (70\% vs $49 \% ; P=0.025$ ) compared with HYBRID patients. OPEN patients manifested more active smoking (59\% vs $37 \% ; P=0.025)$ and less New York Heart Association class III-IV status ( $\%$ vs $14 \% ; P=0.011)$ as opposed to the HYBRID group. A comparison of other common vascular comorbidities such as diabetes, hypertension, dyslipidemia, coronary artery disease, cerebrovascular disease, renal insufficiency, and chronic obstructive pulmonary disease were detected with no significant difference between groups. Interestingly, there also were no differences between the two groups in antiplatelet therapy, statin use, or intervention indication (claudication or CLI). Moreover, HYBRID patients presented with more femoropopliteal and infrapopliteal TASC A type diseases than OPEN patients (19\% vs 5\%

Table I Demographic characteristics, comorbidities, and indications for intervention between groups

\begin{tabular}{|c|c|c|c|}
\hline Characteristic & HYBRID & OPEN & P-value \\
\hline Number of patients & $n=43$ & $\mathrm{n}=64$ & - \\
\hline $\begin{array}{l}\text { Age, mean } \pm \text { standard } \\
\text { deviation, years }\end{array}$ & $70 \pm 10.2$ & $61 \pm 14.5$ & $<0.001$ \\
\hline Male sex & $21(49 \%)$ & $45(70 \%)$ & 0.025 \\
\hline Hypertension & $34(79 \%)$ & $48(75 \%)$ & NS \\
\hline Diabetes mellitus & $19(44 \%)$ & $26(4 I \%)$ & NS \\
\hline Hyperlipidemia & $25(58 \%)$ & $38(60 \%)$ & NS \\
\hline Coronary artery disease & $14(33 \%)$ & $18(28 \%)$ & NS \\
\hline NYHA class III-IV & $6(14 \%)$ & I (2\%) & 0.011 \\
\hline Cerebrovascular disease & $5(11 \%)$ & $6(9 \%)$ & NS \\
\hline COPD & $4(9 \%)$ & $3(5 \%)$ & NS \\
\hline Renal insufficiency & $3(7 \%)$ & $6(9 \%)$ & NS \\
\hline Active smoking & $16(37 \%)$ & 38 (59\%) & 0.025 \\
\hline Antiplatelet therapy & $8(19 \%)$ & $10(17 \%)$ & NS \\
\hline Statin use & $5(11 \%)$ & $6(9 \%)$ & NS \\
\hline \multicolumn{4}{|l|}{ Indications } \\
\hline Claudication & $8(17 \%)$ & $9(14 \%)$ & NS \\
\hline CLI & 35 (83\%) & 55 (86\%) & NS \\
\hline
\end{tabular}

Abbreviations: HYBRID, hybrid (combined surgical and endovascular) procedures; OPEN, open surgical reconstructions; NS, not significant; NYHA, New York Heart Association; COPD, chronic obstructive pulmonary disease; CLI, chronic limb ischemia.
$[P=0.020] ; 21 \%$ vs $6 \%[P=0.023])$, whereas OPEN patients were more likely to be categorized as femoropopliteal TASC II $\mathrm{C} / \mathrm{D}$ (overall rate of $\mathrm{C}$ and $\mathrm{D}$ disease) than HYBRID patients $(83 \%$ vs $63 \% ; P=0.019)$.

\section{Revascularization procedure}

The frequency of the open and endovascular procedures performed in the two groups is presented in Table 3. In the OPEN group, 64 limbs were treated in 97 procedures. The most common procedure was femoropopliteal bypass in 27 patients (15 veins, seven prosthetics, and five composite grafts), followed by femorodistal bypass ( $n=18$; twelve veins, six composite grafts), endarterectomy of the femoral bifurcation in 16 limbs (twelve underwent patch angioplasty), and then popliteal-distal bypass $(n=15$; thirteen veins, two prosthetics) and thrombectomy ( $n=9)$. In the HYBRID group, the open procedure portion was for inflow in 29 cases, outflow in eleven cases, and both inflow and outflow lesions in three cases. The open surgical procedure was a femoropopliteal bypass in 16 patients, patch angioplasty in 15 patients, popliteal-distal bypass in ten patients, and both patch and interposition in two patients. Endovascular procedures in the HYBRID group included angioplasty and stenting in the arterial axes upward and/or downward from the site of open surgery. The angioplasty sites were the superficial femoral arteries $(n=25)$, popliteal arteries $(n=16)$, and infrapopliteal

Table 2 Anatomic characteristics of patients by intervention type

\begin{tabular}{llll}
\hline Characteristic & $\begin{array}{l}\text { HYBRID } \\
(\mathbf{n}=\mathbf{4 3})\end{array}$ & $\begin{array}{l}\text { OPEN } \\
(\mathbf{n}=64)\end{array}$ & P-value \\
\hline Femoropopliteal Trans-Atlantic & Inter-Society Consensus II \\
A & $8(19 \%)$ & $3(5 \%)$ & 0.020 \\
B & $8(19 \%)$ & $8(13 \%)$ & NS \\
C & $11(26 \%)$ & $19(44 \%)$ & NS \\
D & $16(37 \%)$ & $34(53 \%)$ & NS \\
A/B & $16(37 \%)$ & $11(17 \%)$ & 0.019 \\
C/D & $27(63 \%)$ & $53(83 \%)$ & 0.019 \\
Infrapopliteal Trans-Atlantic Inter-Society Consensus & \\
A & $9(21 \%)$ & $4(6 \%)$ & 0.023 \\
B & $8(19 \%)$ & $11(17 \%)$ & NS \\
C & $14(33 \%)$ & $21(33 \%)$ & NS \\
D & $12(28 \%)$ & $28(44 \%)$ & NS \\
A/B & $17(40 \%)$ & $15(23 \%)$ & NS \\
C/D & $26(60 \%)$ & $49(77 \%)$ & NS \\
Number of patent tibial vessels & & & \\
0 & 0 & 0 & NS \\
I & $18(42 \%)$ & $21(33 \%)$ & NS \\
2 & $17(40 \%)$ & $29(45 \%)$ & NS \\
3 & $8(19 \%)$ & $14(22 \%)$ & NS \\
\hline Ab & & &
\end{tabular}

Abbreviations: HYBRID, hybrid (combined surgical and endovascular) procedures; OPEN, open surgical reconstructions; NS, not significant. 
Table 3 Types of open and endovascular procedures between groups

\begin{tabular}{lll}
\hline Procedure & $\begin{array}{l}\text { OPEN } \\
(\mathbf{n = 6 4 )}\end{array}$ & $\begin{array}{l}\text { HYBRID } \\
(\mathbf{n = 4 3 )}\end{array}$ \\
\hline Open procedure & 16 & 19 \\
Femoral bifurcation endarterectomy & 12 & 15 \\
Patch angioplasty & 27 & 16 \\
Femoropopliteal bypass & 18 & - \\
Femorodistal bypass & 15 & 10 \\
Popliteal-distal bypass & 9 & 4 \\
Thrombectomy & & \\
Endovascular procedure & - & 7 \\
TA, femoral artery & - & 18 \\
TA/stent, femoral artery & - & 11 \\
TA, popliteal artery & - & 5 \\
TA/stent, popliteal artery & - & 9 \\
TA, infrapopliteal arteries & - & 3 \\
Catheter thrombolysis & & \\
\hline
\end{tabular}

Abbreviations: HYBRID, hybrid (combined surgical and endovascular) procedures; OPEN, open surgical reconstructions; TA, transluminal balloon angioplasty.

arteries $(n=9)$. Stents were deployed in 18 of 25 superficial femoral lesions and five of 16 popliteal lesions, which were all above knee popliteal segment.

\section{Immediate results}

Overall technical success was achieved in 63 (98\%) of 64 cases in the OPEN group and 41 (95\%) of 43 cases in the HYBRID group. Before discharge, the ABI at rest increased significantly from $0.42 \pm 0.19$ to $0.80 \pm 0.24(P=0.007)$ in OPEN and from $0.34 \pm 0.21$ to $0.83 \pm 0.13(P<0.001)$ in HYBRID. In the OPEN group, the clinical status improved greatly ( +3 Rutherford categories) in 40 patients $(63 \%)$, there was a moderate improvement ( +2 Rutherford categories) in 18 patients (28\%), and six patients $(9 \%)$ had only minor improvement (+1 Rutherford category), whereas in the HYBRID group, great, moderate, and minor improvements were seen in $26(60 \%), 14(33 \%)$, and 3 (7\%) patients, respectively. Perioperative complications of the two groups are listed in Table 4. One cardiac death occurred in the series as whole, for a mortality rate of $0.8 \%$ (1.4\% for the OPEN group, $0 \%$ for the HYBRID group). Two deep infections involving the grafts occurred in the OPEN group, one preserved after debridement and vacuum-assisted closure and the other eventually removed 21 days postoperatively, and received an extra anatomic bypass. Although each complication rate was similar between the groups, the overall rates of complications were significantly higher in the OPEN as opposed to the HYBRID group ( $28 \%$ vs $12 \% ; P=0.042$ ). In addition, the length of stay was significantly less in the
Table 4 Perioperative morbidity for concomitant procedures

\begin{tabular}{llll}
\hline & $\begin{array}{l}\text { OPEN } \\
(\mathbf{n}=\mathbf{6 4})\end{array}$ & $\begin{array}{l}\text { HYBRID } \\
(\mathbf{n}=\mathbf{4 3})\end{array}$ & P-value \\
\hline Death & $\mathrm{I}(\mathrm{I} .5 \%)$ & 0 & $\mathrm{NS}$ \\
Myocardial infarction & $2(3.1 \%)$ & $\mathrm{I}(2.3 \%)$ & $\mathrm{NS}$ \\
Wound infection & $3(4.6 \%)$ & $\mathrm{I}(2.3 \%)$ & $\mathrm{NS}$ \\
Hematoma & $3(4.6 \%)$ & $\mathrm{I}(2.3 \%)$ & $\mathrm{NS}$ \\
Lymph leak & $2(3.1 \%)$ & $\mathrm{I}(2.3 \%)$ & $\mathrm{NS}$ \\
Graft infection/erosion & $2(3.1 \%)$ & 0 & $\mathrm{NS}$ \\
Pneumonia & $2(3.1 \%)$ & 0 & $\mathrm{NS}$ \\
Stroke & $\mathrm{I}(\mathrm{I} .5 \%)$ & 0 & $\mathrm{NS}$ \\
Emergency reoperation & $2(3.1 \%)$ & $\mathrm{I}(2.3 \%)$ & $\mathrm{NS}$ \\
Total morbidity & $\mathrm{I}(28 \%)$ & $5(12 \%)$ & 0.042 \\
\hline
\end{tabular}

Abbreviations: HYBRID, hybrid (combined surgical and endovascular) procedures; OPEN, open surgical reconstructions; NS, not significant.

HYBRID group ( $7.6 \pm 12.0$ days) than in the OPEN group (15.5 \pm 17.3 days; $P=0.018$ ).

\section{Outcome on follow-up}

Mean follow-up was 28.2 \pm 19.1 months (median, 28.2 months; range, $0-50$ months). Kaplan-Meier survival analysis did not show any statistically significant difference in 36-month primary $(47.1 \% \pm 7.1 \%$ vs $50.1 \% \pm 9.4 \% ; P=0.418)$, assisted primary $(57.0 \% \pm 7.9 \%$ vs $62.4 \% \pm 9.2 \% ; P=0.517)$, or secondary $(82.0 \% \pm 6.8 \%$ vs $83.1 \% \pm 7.3 \% ; P=0.445)$ patency between the HYBRID and OPEN groups (Figures 1-3). Loss of primary patency occurred in 23 patients in the OPEN group between 0 and 48 months. Overall, $87 \%(20 / 23)$ of loss of primary patency was caused by graft-related events, of which nine

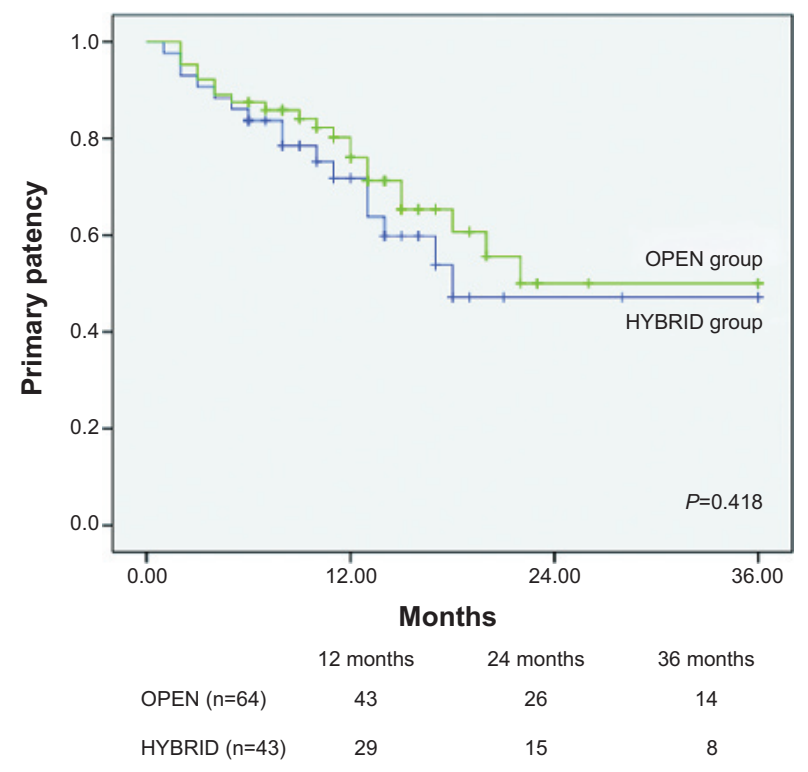

Figure I Primary patency rates of the OPEN and HYBRID groups.

Note: There was no statistical difference between the two groups (Kaplan-Meier analysis, log-rank test, $P=0.418$ ).

Abbreviations: HYBRID, hybrid (combined surgical and endovascular) procedures; OPEN, open surgical reconstructions. 


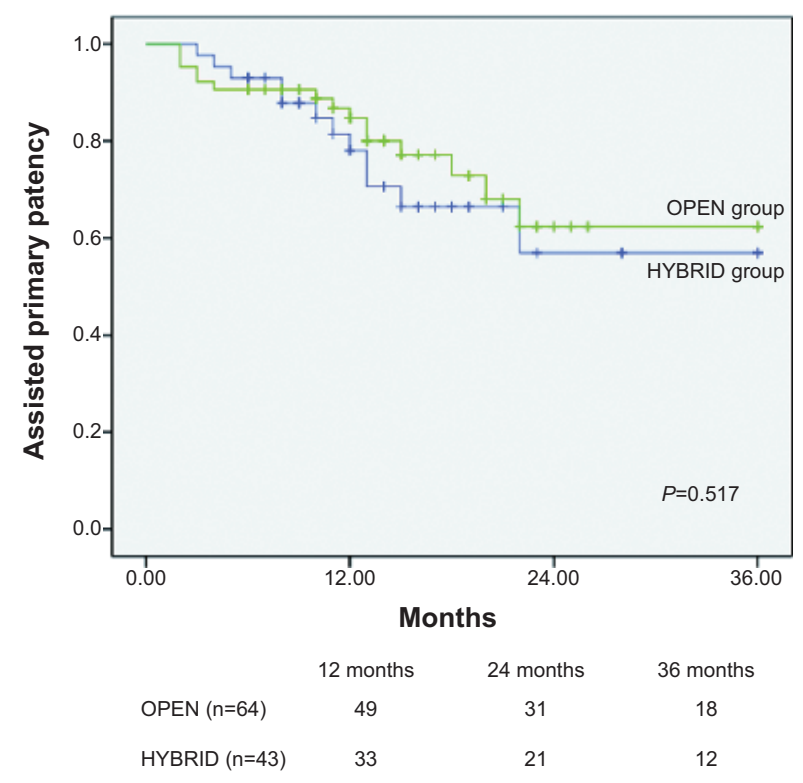

Figure 2 Assisted primary patency rates of the OPEN and HYBRID groups. Note: There was no statistical difference between the two groups (Kaplan-Meier analysis, log-rank test, $P=0.517$ ).

Abbreviations: HYBRID, hybrid (combined surgical and endovascular) procedures; OPEN, open surgical reconstructions.

patients had graft thrombectomies and anastomotic revisions, four had redo bypasses, three had anastomosis percutaneous transluminal angioplasty (PTA), one had graft infection necessitating graft removal, and three had amputations resulting from advanced foot ischemia. Two patients with patent popliteal-distal bypasses had femoral bifurcation restenosis that needed endarterectomy/patch angioplasty. Two patients

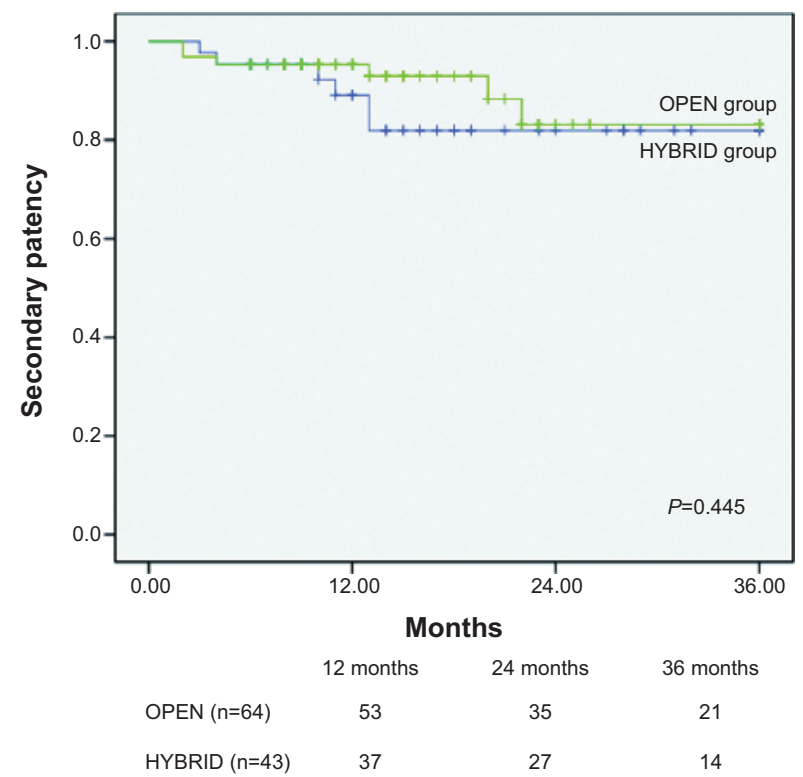

Figure 3 Secondary patency rates of OPEN and HYBRID groups.

Note: There was no statistical difference between the two groups (Kaplan-Meier analysis, log-rank test, $P=0.445$ ).

Abbreviations: HYBRID, hybrid (combined surgical and endovascular) procedures; OPEN, open surgical reconstructions. eventually underwent amputations after the occlusion of redo bypasses. Loss of primary patency occurred in 18 patients in the HYBRID group between 0 and 42 months, eleven of which were related to abnormalities detected in the endovascular treated segments (67\%) and seven related to the bypass. In the six patients who needed interventions for maintaining patency, three had PTA and stenting of their SFA, two had PTA of infrapopliteal restenosis, and one needed angioplasty of the endarterectomized segment. Of the 12 occlusions, four had thrombolysis followed by PTA/restenting of SFA or popliteal arteries, three had bypass graft thrombectomies and revisions, two had femoral-popliteal bypass, two patients had amputations because of unhealing wounds, and one had recanalization of tibioperoneal trunk. Overall, there were four amputations in this group. Limb salvage rates of patients with critical limb ischemia were similar at 36 months in the HYBRID and OPEN groups $(76.3 \% \pm 9.3 \%$ vs $80.4 \% \pm 8.2 \%$; $P=0.579$; Figure 4). We used Cox regression analysis to determine predictors of failure for the entire cohort of patients, which demonstrated that CLI was the only negative predictor of primary patency in the entire patient cohort. No additional factors, including age, sex, hypertension, diabetes, hyperlipidemia, renal insufficiency, current smoking, antiplatelet therapy, and statin use, were found to affect primary patency. We also looked at the predictors of patency of two groups independently. Predictors of failure of the OPEN group were active smoking, CLI, and lack of statin therapy. Predictors of failure of HYBRID group were CLI, renal insufficiency, and

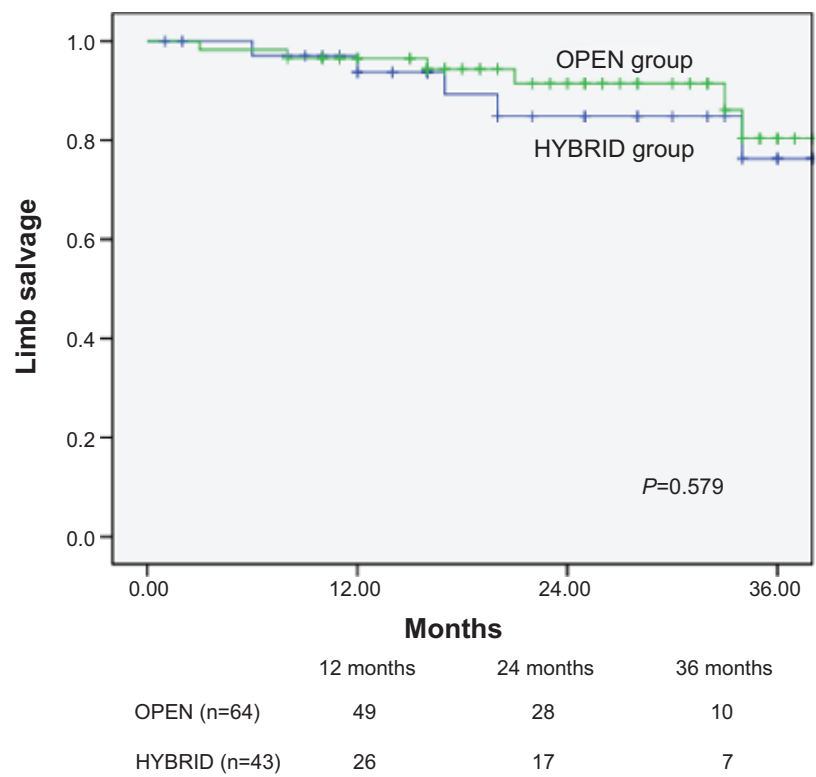

Figure 4 Limb salvage rates of OPEN and HYBRID groups.

Note: There was no statistical difference between the two groups (Kaplan-Meier analysis, log-rank test, $P=0.579$ ).

Abbreviations: HYBRID, hybrid (combined surgical and endovascular) procedures; OPEN, open surgical reconstructions. 
diabetes. Interestingly, neither the TASC classification nor the number of patent tibial arteries predicted any patency rate in either group, which was previously reported as predictors of PTA/stenting or bypass failure (Table 5).

\section{Discussion}

The treatment of MIOD often requires complete revascularization of all affected levels to renew blood flow to the pedal circulation. The revascularization of one level alone is often insufficient and seldom leads to relief from rest pain and the healing of ulcer or gangrene. ${ }^{12}$ Conventional open surgical management of such lesions required extensive revascularization and lengthy procedure, commonly associated with significant morbidity and mortality and typically reserved for physiologically younger, "healthy" patients. ${ }^{13}$ Endovascular interventions should be preferred for the elderly, high-risk patients, but in practice we often encountered situations in which it was difficult to proceed with angioplasty solely because of simultaneous calcifications and stenosis of the multilevel arteries. ${ }^{14,15}$ The hybrid procedures offer a solution for such vascular lesions in which endovascular treatment may be used for in-flow or out-flow lesions, in combination with open surgery, during a single session. ${ }^{16,17}$

In our center, hybrid procedures initially consisted of selective use of endovascular interventions for simple lesions (TASC A or B), but with our increasing experience, the hybrid procedures started to include patients whose endovascular treated segment had complex disease (TASC C or D), subsequently decreasing the frequency of open reconstruction. At this time, the most common combinations of our hybrid procedure for MIOD were CFA

Table 5 Predictors of patency by Cox proportional hazard models

\begin{tabular}{lll}
\hline & $\begin{array}{l}\text { Hazard ratio (95\% } \\
\text { confidence interval) }\end{array}$ & P-value \\
\hline $\begin{array}{l}\text { Overall cohort } \\
\text { Chronic limb ischemia }\end{array}$ & $2.986(1.365-6.410)$ & 0.0133 \\
$\begin{array}{l}\text { OPEN versus HYBRID } \\
\text { Procedure-specific model }\end{array}$ & $1.069(0.586-1.937)$ & 0.7987 \\
OPEN & & \\
$\quad$ Not taking statin & $2.573(1.243-5.326)$ & 0.0109 \\
$\quad$ Active smoking & $3.210(1.321-4.832)$ & 0.0089 \\
$\quad$ Chronic limb ischemia & $2.832(1.012-3.238)$ & 0.0121 \\
HYBRID & $3.012(1.199-7.576)$ & 0.0189 \\
$\quad$ Renal insufficiency & $2.313(1.232-5.320)$ & 0.0165 \\
$\quad \begin{array}{l}\text { Diabetes } \\
\text { Chronic limb ischemia }\end{array}$ & $10.753(3.831-30.030)$ & $<0.0001$ \\
\hline
\end{tabular}

Abbreviations: HYBRID, hybrid (combined surgical and endovascular) procedures; OPEN, open surgical reconstructions. endarterectomy with infrainguinal angioplasty, infrainguinal reconstruction (above-knee bypass) with infrapopliteal angioplasty, and a combination of SFA angioplasty with popliteal-distal bypass. Some important technical aspects of the hybrid procedure could be gleaned from our study and other reports. ${ }^{18-21}$ The first technical point was the placement of the guidewire for the interventional component initially before endarterectomy, or even arteriotomy. Once we crossed the occlusion, we left the wires in place and performed the surgical component of the procedure. This allowed continuous, direct blood flow to the extremity that improved the quality of angiographic image and, at the same time, avoided the stagnant blood in the endovascular treated segment resulting from arteries clamping and protected that site from thrombosis. The second technical point was to ensure that the interface between open and endovascular treated segments was lesion-free or have no need for further intervention. Partial overlap of stent and previous patching in SFA was sometimes mandatory to avoid the recurrence due to untreated segment between stent and patch. The third point was the routine use of angiography at the end of the intervention, which verified renewed blood flow at the level of all lesions and minimized immediate failure.

The efficacy of the hybrid procedure has been previously documented. Antoniou and colleagues, in a recent report of a heterogeneous cohort of patients ( $47 \%$ with CLI), using a variety of different types of reconstructive procedures, reported primary and secondary patency rates at 12 months of $71 \%$ and $98 \%$, respectively. ${ }^{10}$ Matsagkas and colleagues reported immediate and midterm results of hybrid procedure for lower extremities with CLI. ${ }^{22}$ The primary and secondary patency rates at 24 months were $93.2 \%$ and $95.5 \%$, respectively. Cotroneo and colleagues followed 44 patients ( 24 with claudication and 20 with CLI) after hybrid procedures and reported 2-year primary and secondary patency rates of 79.1\% and $86.1 \%$, respectively. ${ }^{8}$ Nishibe and coworkers reported a 3-year experience with hybrid procedure for multifocal peripheral TASC D lesions. The primary patency rates were $94 \%, 70 \%$, and $70 \%$ at 6,12 , and 24 months, respectively, and the primary assisted patency rate was $94 \%$ at 24 months. The limb salvage rate was $100 \%$ at 24 months. ${ }^{9}$ The long-term results of hybrid procedure were also excellent. Chang and colleagues reported 5-year primary, primary assisted, and secondary patency of $60 \%, 97 \%$, and $98 \%$, respectively. ${ }^{23}$ However, none of the above studies focused on the population suffering from infrainguinal arterial disease. Thus, the present study was constructed to investigate whether HYBRID could be performed with equivalent safety, efficacy, and durability as OPEN in MIOD patients. 
Our study population included 107 patients with significant comorbid risk factors who predominantly presented with CLI. Despite the nonrandomized nature of this study, the two groups undergoing OPEN or HYBRID were well matched for most risk factors, TASC classification, and other salient clinical variables. However, the patients who underwent OPEN were much older and presented with more New York Heart Association class III-IV status than HYBRID patients, which might be explained by our preference to treat old patients with poor conditions by HYBRID, rather than OPEN. The immediate results, including technical success, ABI and clinical status improvement, and mortality rates were similar between two groups, but with a higher total perioperative morbidity rate and a longer length of stay in OPEN patients compared with HYBRID patients. Analysis of late results showed that the OPEN group had higher primary, assisted primary, and secondary patency at 3 years than OPEN groups but did not show any statistically significant difference, which means patency rates after the hybrid procedure could compete with those with open reconstructive surgery in this cohort. It is important to note that the patency rates in our patients are comparable to those in the literature, ${ }^{5}$ although it is very difficult to make meaningful comparisons because of the heterogeneity of the cases in published series.

Several factors that might influence long-term patency after the revascularization of MIOD were analyzed in our studies, including anatomic, comorbid attributes and indications. The only negative predictor of patency of overall patients was CLI, suggesting that clinical presentation might be a more accurate predictor of patency than the specific location or severity of stenosis in the presence of MIOD. In addition, renal insufficiency and diabetes were another two negative predictors of primary patency after hybrid procedure, and active smoking or no taking of statins might compromise the durability of open reconstruction. The choice of type of intervention did not predict failure; therefore, if patient selection were appropriate, either procedure to treat patients with MIOD should lead to equivocal results. Another important finding in this series, in contrast to previously published data, ${ }^{24,25}$ was that neither TASC classification nor the number of patent tibial vessels was a predictor of primary patency in either the OPEN or the HYBRID group.

Several limitations to our study need to be addressed. The main limitation was that it was a retrospective and nonrandomized study and that the number of patients in each group was relatively small. Unfortunately, with the preference for less-invasive therapies and procedural selection based on operative risk, it might be a difficult trial to complete with regard to patient recruitment and enrollment. Because of the heterogeneity of the anatomic and clinical presentation of solely endovascular treated patients, it was almost impossible to have such an endovascular group comparable with the HYBRID group. In addition, members of the HYBRID group were much older and had more TASC C/D than those in the OPEN group; these factors, however, did not have any effect on patency rates, and therefore did not seem to have any significant effect on our overall findings.

\section{Conclusion}

To our knowledge, no other published study has compared the technique of hybrid procedure with open repair for the treatment of MIOD. The results of our study clearly confirmed that MIOD could be treated by HYBRID with shorter hospitalization and similar early and long-term efficacy when compared with OPEN. HYBRID should be considered for the MIOD patients with high surgical risks; however, diabetes, renal insufficiency, and CLI could compromise its long-term patency.

\section{Disclosure}

The authors report no conflicts of interest in this work.

\section{References}

1. Lyden SP, Smouse HB. TASC II and the endovascular management of infrainguinal disease. J Endovasc Ther. 2009;16(2)(suppl 2):II5-II18.

2. Norgren L, Hiatt WR, Dormandy JA, Nehler MR, Harris KA, Fowkes FG; TASC II Working Group. Inter-Society Consensus for the Management of Peripheral Arterial Disease (TASC II). J Vasc Surg. 2007;45 Suppl S:S5-S67.

3. Van Den Berg J, Waser S, Trelle S, Diehm N, Baumgartner I. Lesion characteristics of patients with chronic critical limb ischemia that determine choice of treatment modality. J Cardiovasc Surg (Torino). 2012;53(1):45-52.

4. Dougherty MJ, Young LP, Calligaro KD. One hundred twenty-five concomitant endovascular and open procedures for lower extremity arterial disease. J Vasc Surg. 2003;37(2):316-322.

5. Balaz P, Rokosny S, Bafrnec J, Björck M. The role of hybrid procedures in the management of peripheral vascular disease. Scand J Surg. 2012; 101(4):232-237.

6. Dosluoglu HH, Lall P, Cherr GS, Harris LM, Dryjski ML. Role of simple and complex hybrid revascularization procedures for symptomatic lower extremity occlusive disease. J Vasc Surg. 2010;51(6):1425-1435.e1.

7. Ebaugh JL, Gagnon D, Owens CD, Conte MS, Raffetto JD. Comparison of costs of staged versus simultaneous lower extremity arterial hybrid procedures. Am J Surg. 2008;196(5):634-640.

8. Cotroneo AR, Iezzi R, Marano G, Fonio P, Nessi F, Gandini G. Hybrid therapy in patients with complex peripheral multifocal steno-obstructive vascular disease: two-year results. Cardiovasc Intervent Radiol. 2007; 30(3):355-361.

9. Nishibe T, Kondo Y, Dardik A, Muto A, Koizumi J, Nishibe M. Hybrid surgical and endovascular therapy in multifocal peripheral TASC D lesions: up to three-year follow-up. J Cardiovasc Surg (Torino). 2009; 50(4):493-499. 
10. Antoniou GA, Sfyroeras GS, Karathanos C, et al. Hybrid endovascular and open treatment of severe multilevel lower extremity arterial disease. Eur J Vasc Endovasc Surg. 2009;38(5):616-622.

11. Rutherford RB, Baker JD, Ernst C, et al. Recommended standards for reports dealing with lower extremity ischemia: revised version. J Vasc Surg. 1997;26(3):517-538.

12. Fernandez N, McEnaney R, Marone LK, et al. Multilevel versus isolated endovascular tibial interventions for critical limb ischemia. J Vasc Surg. 2011;54(3):722-729.

13. Matsagkas M, Kouvelos G, Arnaoutoglou E, Papa N, Labropoulos N, Tassiopoulos A. Hybrid procedures for patients with critical limb ischemia and severe common femoral artery atherosclerosis. Ann Vasc Surg. 2011;25(8):1063-1069.

14. Conrad MF, Crawford RS, Hackney LA, et al. Endovascular management of patients with critical limb ischemia. J Vasc Surg. 2011;53(4): $1020-1025$.

15. Gargiulo NJ III, O'Connor DJ. Proportion of patients with critical limb ischemia who require an open surgical procedure in a center favoring endovascular treatment. Am Surg. 2011;77(3):315-321.

16. Piazza M, Ricotta JJ II, Bower TC, et al. Iliac artery stenting combined with open femoral endarterectomy is as effective as open surgical reconstruction for severe iliac and common femoral occlusive disease. J Vasc Surg. 2011;54(2):402-411.

17. Lantis J, Jensen M, Benvenisty A, Mendes D, Gendics C, Todd G. Outcomes of combined superficial femoral endovascular revascularization and popliteal to distal bypass for patients with tissue loss. Ann Vasc Surg. 2008;22(3):366-371.
18. Dosluoglu HH, Cherr GS. Pre-arteriotomy guidewire access (PAGA): a crucial maneuver for securing inflow and/or outflow in patients with bulky iliofemoral occlusive disease undergoing combined (open/endovascular) procedures. Eur J Vasc Endovasc Surg. 2006;32(1):97-100.

19. Reed AB. Endovascular as an open adjunct: use of hybrid endovascular treatment in the SFA. Semin Vasc Surg. 2008;21(4):200-203.

20. Reed AB. Hybrid procedures and distal origin grafts. Semin Vasc Surg. 2009;22(4):240-244.

21. Schrijver AM, Moll FL, De Vries JP. Hybrid procedures for peripheral obstructive disease. J Cardiovasc Surg (Torino). 2010;51(6):833-843.

22. Matsagkas M, Kouvelos G, Arnaoutoglou E, Papa N, Labropoulos N, Tassiopoulos A. Hybrid procedures for patients with critical limb ischemia and severe common femoral artery atherosclerosis. Ann Vasc Surg. 2011;25(8):1063-1069.

23. Chang RW, Goodney PP, Baek JH, Nolan BW, Rzucidlo EM, Powell RJ. Long-term results of combined common femoral endarterectomy and iliac stenting/stent grafting for occlusive disease. J Vasc Surg. 2008;48(2):362-367.

24. Ihnat DM, Duong ST, Taylor ZC, et al. Contemporary outcomes after superficial femoral artery angioplasty and stenting: the influence of TASC classification and runoff score. J Vasc Surg. 2008;47(5):967-974.

25. Scali ST, Rzucidlo EM, Bjerke AA, et al. Long-term results of open and endovascular revascularization of superficial femoral artery occlusive disease. J Vasc Surg. 2011;54(3):714-721.
Clinical Interventions in Aging

\section{Publish your work in this journal}

Clinical Interventions in Aging is an international, peer-reviewed journal focusing on evidence-based reports on the value or lack thereof of treatments intended to prevent or delay the onset of maladaptive correlates of aging in human beings. This journal is indexed on PubMed Central, MedLine,

\section{Dovepress}

CAS, Scopus and the Elsevier Bibliographic databases. The manuscript management system is completely online and includes a very quick and fair peer-review system, which is all easy to use. Visit http://www.dovepress. com/testimonials.php to read real quotes from published authors. 